\title{
ESTUDO DE TEMPO E MOVIMENTO NA ETAPA DE SELEÇÃO DE MUDAS EM UM VIVEIRO FLORESTAL
}

\author{
Juliana de Lima Gonçalves ${ }^{1}$, Nelson Yoshihiro Nakajima ${ }^{2}$, Roberto Tuyoshi Hosokawa ${ }^{2}$, \\ Crismeire Isbaex ${ }^{3}$, Pompeu Paes Guimarães ${ }^{4}$, Felipe Quartucci ${ }^{5}$ \\ ${ }^{1}$ Eng $^{\mathrm{a}}$. Florestal, Capão Bonito, SP, Brasil - jlgoncalves84@yahoo.com.br \\ ${ }^{2}$ Eng. Florestal, Depto. de Ciências Florestais, UFPR, Curitiba, PR, Brasil - nelson.nakajima@ufpr.br; hosokawa@pq.cnpq.br \\ ${ }^{3}$ Eng $^{\mathrm{a}}$. Florestal, M.Sc, Depto. de Engenharia Florestal, UFV, Viçosa, MG, Brasil - crismeireisbaex@hotmail.com \\ ${ }^{4}$ Eng. Florestal, Doutorando em Eng. Florestal, UFPR, Curitiba, PR. Brasil - pompeupaes@yahoo.com.br \\ ${ }^{5}$ Eng. Florestal, M.Sc., São Paulo, SP. Brasil - felipequartucci@ hotmail.com \\ Recebido para publicação: 11/09/2012 - Aceito para publicação: 09/04/2014
}

\begin{abstract}
Resumo
O objetivo deste artigo foi analisar a viabilidade da melhoria das condições de trabalho em um viveiro florestal adotando um ambiente protegido. A pesquisa focaliza o processo de seleção de mudas pelo estudo de tempo e movimento. Uma análise de viabilidade econômica utilizando os indicadores VPL e TIR foi realizada, levando em conta os tempos perdidos no processo e o custo de implantação de um galpão de seleção. $\mathrm{O}$ estudo de tempo mostrou que se essas atividades forem realizadas em um ambiente coberto, protegido e adequado, sem interferência de intempéries, proporcionará melhoria das condições de trabalho e aperfeiçoará o rendimento da produção. A análise de viabilidade econômica mostrou que, com base nos ganhos de rendimento calculados, o investimento total na construção do galpão é totalmente viável e o retorno financeiro do investimento acontecerá em dois anos, com um VPL de R \$ $119.150,27$, uma TIR de 14,5\% e uma taxa de $8 \%$ ao ano. A construção do galpão possibilitará um ambiente de trabalho mais confortável para o trabalhador, economizando tempo das seleções de mudas e redução de custos da produção.

Palavra-chave: Melhoria ergonômica; análise econômica; processo produtivo.
\end{abstract}

\begin{abstract}
Time and movement study in forest nursery. The objective of this research was to analyze the improvement of work conditions in a forest nursery by adopting a protected environment. The research focuses on the process of seedlings selections by the study of time and movement. It performed an economic viability assessment utilizing the indicators NPV and IRR, and considering the downtime in the process and costs of implementing a selection warehouse. The time and movement study showed that, if these activities were performed in a covered, protected and appropriate environment, without direct interference of weather, they will provide improvement of work conditions and optimize income productivity. The economic viability assessment showed that, based on calculated income gains, the overall investment used in the construction of a warehouse is fully viable and the financial return on the investment will happen in two years, with a NPV of R\$ $119,150.27$, an IRR of $14.5 \%$, using a $8 \%$ discount rate. The warehouse construction will enable a more comfortable work environment for the worker, saving time of seedling selections and reduction in production costs.
\end{abstract}

Keywords: Ergonomic improvement; economic analysis; production process.

\section{INTRODUÇÃO}

O desempenho das atividades do setor florestal passou por muitas mudanças nos últimos anos. A procura por maior competitividade, através da inovação no setor, resultou em novos processos de trabalho, aumentando o rendimento das operações (FIEDLER et al., 1998).

A expansão da área plantada com eucalipto no Brasil é resultado de um conjunto de fatores que vem favorecendo o plantio em larga escala desse gênero. Segundo Schorn e Formento (2003), entre os aspectos mais relevantes está a produção de mudas florestais, pois representa o início de uma cadeia de 
operações que visam o estabelecimento de florestas e povoamentos. Os mesmos autores apontam ainda que o sucesso da implantação e da produção florestal estão diretamente relacionados à qualidade das operações de viveiro e do seu produto, que são as mudas.

Carneiro (1995) denominou viveiro florestal como sendo a área em que são concentradas todas as atividades de produção de mudas, sendo que a produção comercial de mudas de eucalipto, na maioria das empresas florestais, é realizada por meio de propagação vegetativa e em viveiros permanentes (XAVIER; COMÉRIO, 1996).

De acordo com Melo (2009), a produção de mudas através de miniestaquia pode ser conduzida nas fases de produção por intermédio de brotos em minijardim clonal, indução do enraizamento adventício em casa de vegetação climatizada, aclimatação à sombra, crescimento e rustificação. Dessa maneira, a otimização das operações em cada uma dessas fases contribui para o sucesso da produção de mudas (FERREIRA et. al., 2004).

A produção de mudas em viveiros constitui a primeira etapa da atividade florestal, tanto por propagação vegetativa como por sementes (MARTINS et al., 1998). Situações envolvendo o meio físico no qual se efetuam as atividades de propagação de plantas merecem estudos ergonômicos para quantificar seus níveis, melhorando o ambiente de trabalho (ALVES et al., 2002).

A ergonomia é a ciência que se preocupa com os aspectos humanos no trabalho em qualquer situação onde este é realizado (MONTEIRO, 2009). Dessa forma, oferece menor risco e maior conforto no posto de trabalho, melhorando a produtividade, assim como a otimização dos esforços e movimentos no desenvolvimento das tarefas, reduzindo a probabilidade de erros (VIEIRA, 1997).

A aplicação dos estudos ergonômicos nas operações de produção de mudas visa amenizar a fadiga física e mental dos trabalhadores e aumentar a satisfação, segurança e bem-estar, levando, consequentemente, à melhoria da qualidade e produtividade das mudas (FIEDLER, 2007).

Entretanto, as atividades nos postos de trabalho precisam ser conhecidas, padronizadas e terem seu desempenho permanentemente mensurado, no sentido de melhorar a produtividade (RUDNER, 2011). Dessa forma, a ergonomia auxilia na gestão da qualidade de todos os processos de produção de mudas.

Segundo Braz (2010), numa operação em andamento, torna-se necessária a cronometragem das atividades para estudos de tempo e racionalização das atividades. Diante da execução de um estudo de tempos, torna-se possível determinar o tempo que uma pessoa adaptada ao trabalho e completamente treinada no método específico levará para executar certa tarefa em um ritmo considerado normal. Esse tempo é denominado de tempo padrão para a operação (BARNES, 1977).

Dessa forma, este estudo teve como objetivo analisar a viabilidade de melhoria das condições de trabalho em um viveiro florestal, através da análise de viabilidade econômica da construção de um galpão coberto e protegido, utilizando-se de estudo de tempo e movimento nas atividades de seleção de mudas.

\section{MATERIAL E MÉTODOS}

O estudo foi realizado em um viveiro de mudas clonais de Eucalyptus sp. no município de Capão Bonito, estado de São Paulo, com as seguintes coordenadas geográficas: latitude $24^{\circ} 00^{\prime 2} 21^{\prime}$ 'sul, longitude $48^{\circ} 20^{\prime} 58^{\prime \prime}$ oeste e altitude de 705 metros. O clima é temperado, com média máxima de $2{ }^{\circ} \mathrm{C}$ e média mínima de $14{ }^{\circ} \mathrm{C}$.

Para realizar a seleção de mudas, utilizou-se uma mesa, que foi transportada por trator até a lateral das quadras e por uma funcionária até o canteiro. O trator percorre toda a extensão do canteiro. Da mesma forma, as bandejas são transportadas (10 bandejas por vez, manualmente ou com carrinho).

A primeira seleção das mudas foi feita quando os propágulos iniciaram o crescimento da parte aérea. Procedeu-se o raleio das mudas das bandejas de 224 para de 96 alojamentos, que consiste em retirar as mortas, por raízes deformadas ou doenças, e separar as mudas enraizadas por tamanho, para que na fase de aclimatação não haja competição. A Figura 1 indica as atividades da primeira seleção de mudas.

A segunda fase de seleção foi feita quando as mudas já estavam bem formadas, alternando-as na bandeja. Consiste em retirar as mudas mortas, assim como a primeira seleção, para melhoria da rustificação e corte das raízes aparentes (aquelas que saem pelo orifício inferior do tubete). Essa seleção é um preparatório para a expedição de mudas. 


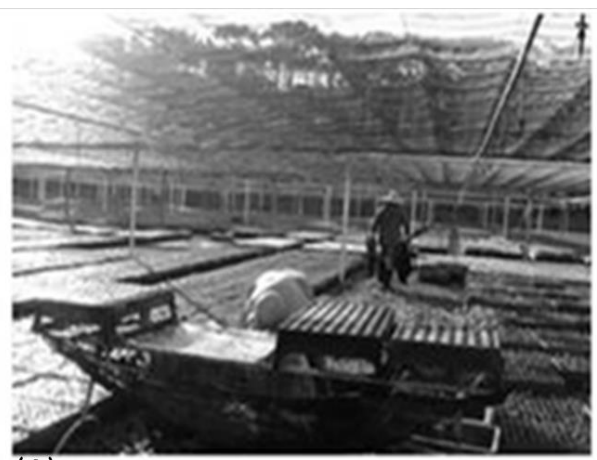

(A)

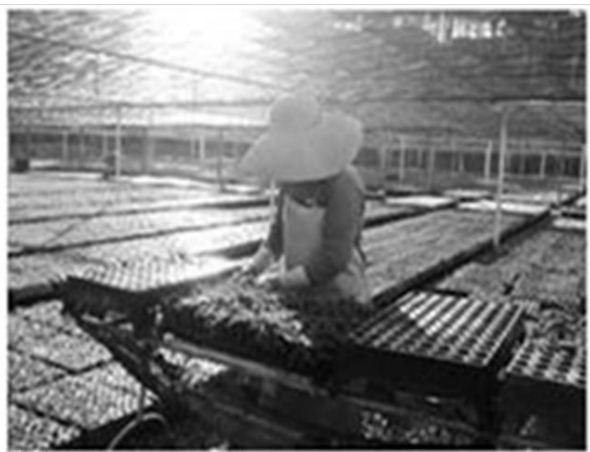

(B)

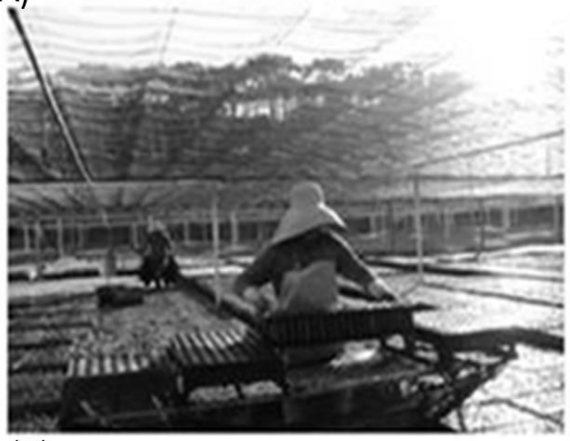

(C)
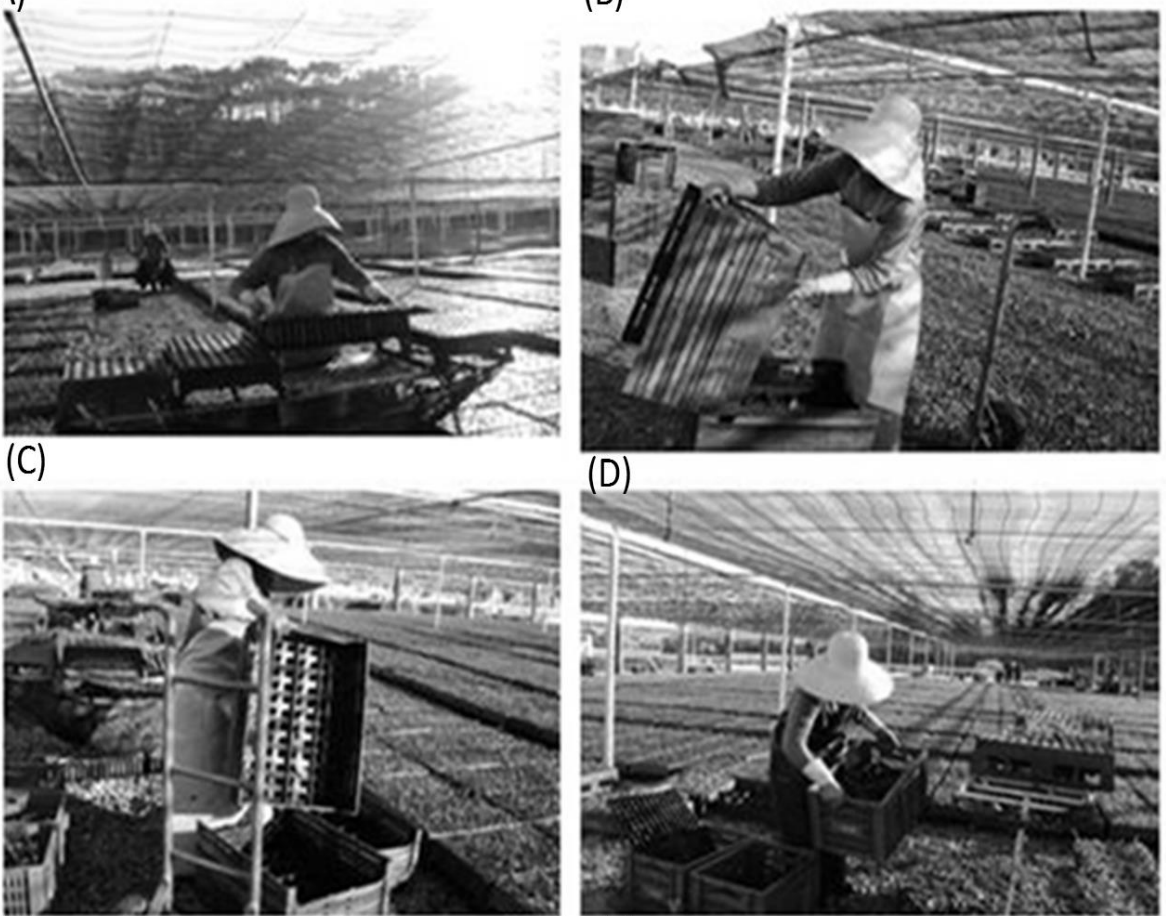

(E)

(D)

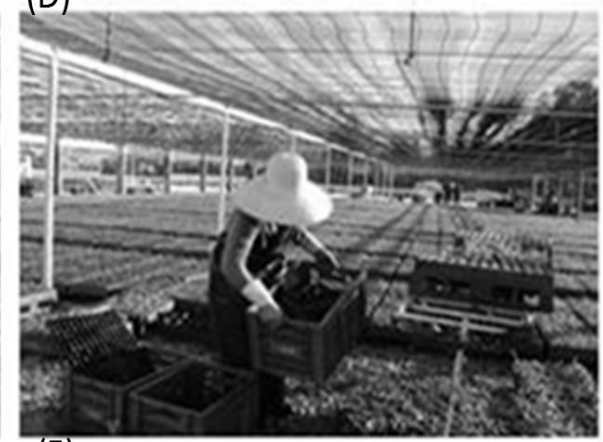

$(F)$

Figura 1. Atividades da primeira seleção de mudas: A) Pegando a bandeja a ser selecionada; B) Selecionando as mudas; C) Colocando a bandeja selecionada no chão; D e E) Pegando bandeja vazia para seleção; F) levando a caixa com as mudas descartadas.

Figure 1. Activities of the first seedlings selection: A) Picking up the tray to be selected; B) Selecting the seedlings; C) Placing the tray selected on the ground, D and E) Picking up empty tray for selection; F) Carrying the box of discarded seedlings.

A figura 2 indica as atividades da segunda seleção de mudas.

A jornada diária de trabalho no viveiro é de 8 horas e 48 minutos. A cada duas horas de trabalho é feito um descanso de 15 minutos e uma pausa de uma hora para almoço. A tabela 1 indica os dados gerais da atividade da primeira e segunda seleção de mudas.

Para a realização do estudo de tempo e movimento, as atividades da primeira e segunda seleção foram divididas em etapas (Tabela 2). A subdivisão do decurso do trabalho em atividades parciais é condição prévia para a realização de estudos de trabalho.

No ponto de medição, é importante limitar de forma precisa e perfeitamente clara as diferentes etapas, fixando início e fim de cada uma. Essa determinação faz-se por meio de pontos de medição, momento em que termina o tempo da atividade parcial anterior e começa o tempo da atividade seguinte. 
Para a definição das classes de tempo e determinação de dados gerenciais da operação, como eficiência e capacidade do equipamento, faz-se necessária a separação das atividades parciais em classes de tempo, conforme metodologia proposta por Gago e Corte (1986):

- Tempo produtivo: tempo em que o trabalhador está efetivamente desempenhando sua função produtiva.

- Parada operacional ou tempo auxiliar: corresponde ao tempo que o trabalhador utiliza para realizar funções auxiliares necessárias à função produtiva, porém sem desempenhar sua função produtiva.

- Paradas não operacionais: o deslocamento entre as quadras entra nesse grupo de tempo.

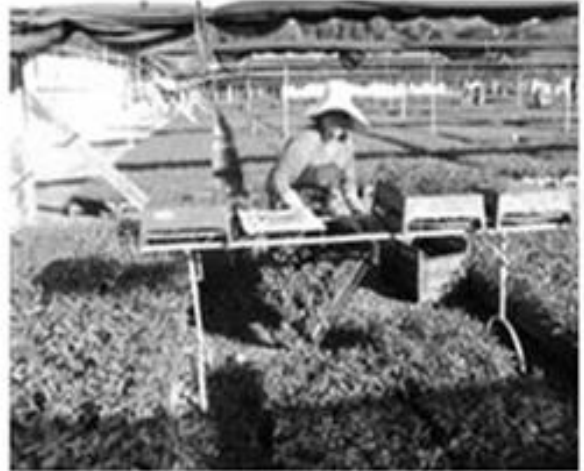

(A)

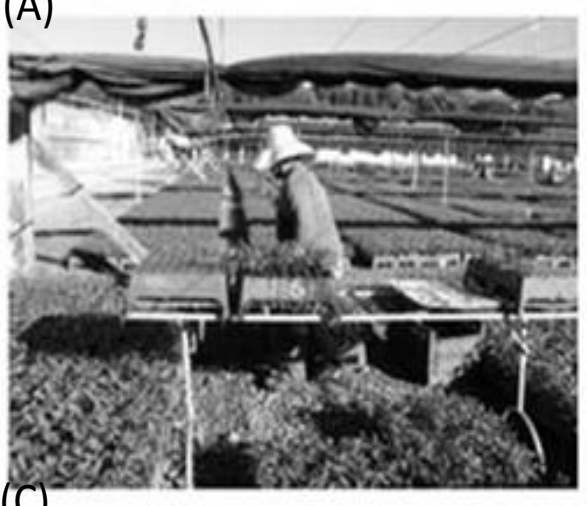

(C)

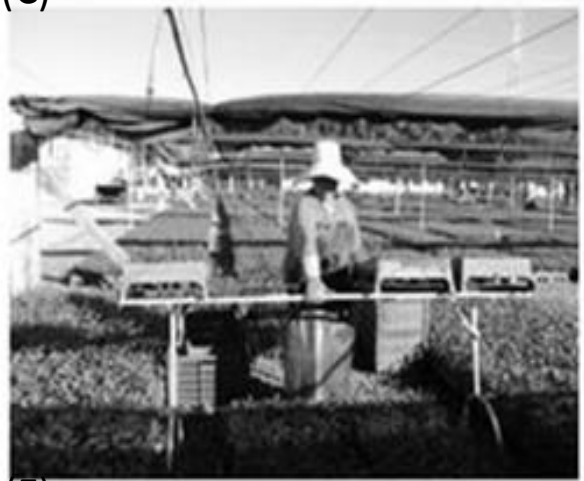

(E)

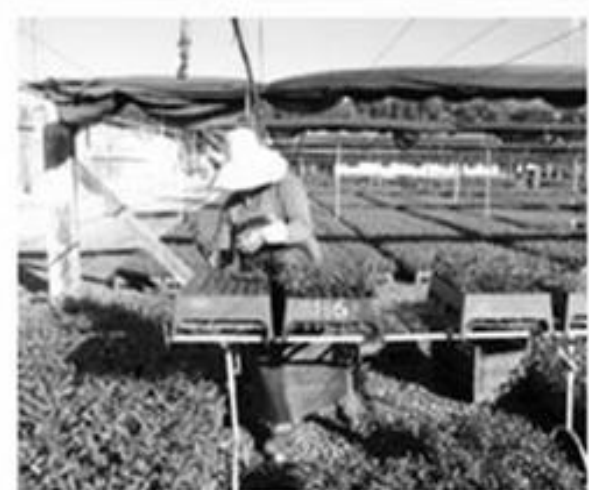

(B)

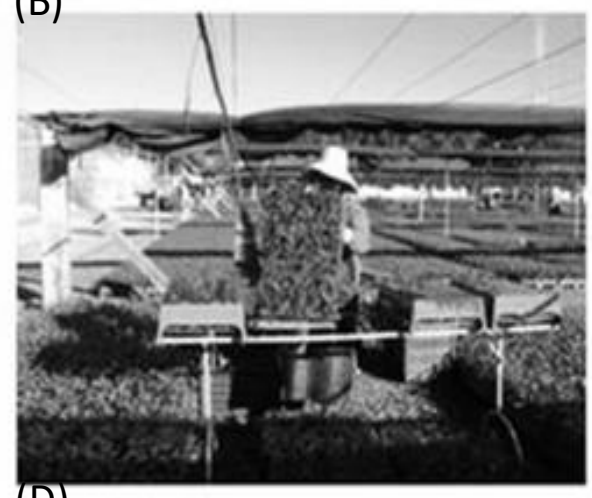

(D)

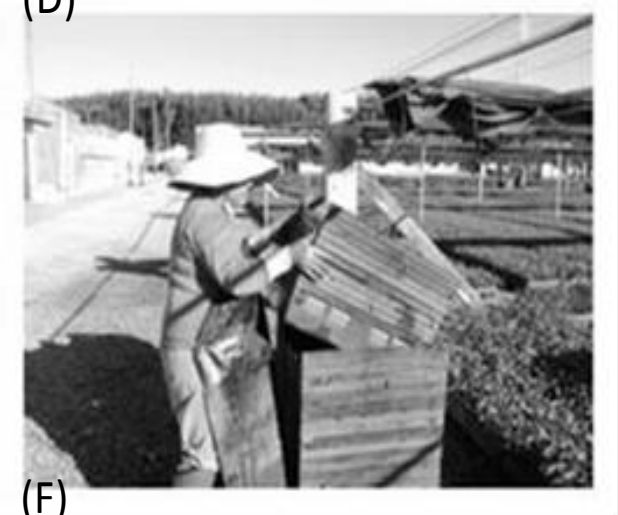

(F)

Figura 2. Atividade da segunda seleção de mudas: A) Pegando a bandeja a ser selecionada; B) Selecionando as mudas; C) Colocando a bandeja selecionada no chão; D) cortando as raízes sobressalentes; E) Avançando com a mesa sobre o canteiro; F) Pegando bandejas vazias para seleção.

Figure 2. Activities of the second seedlings selection: A) Picking up the tray to be selected; B) Selecting the seedlings; C) Placing the tray selected on the ground; D) Cutting the salient roots; E) Moving forward with the table; F) Picking up empty tray for selection. 
Tabela 1. Descrição dos materiais e dados gerais da primeira e segunda seleção.

Table 1. Material description and general data from the first and second selection.

\begin{tabular}{lll}
\hline Dados & $\mathbf{1}^{\mathbf{a}}$ Seleção & $\mathbf{2}^{\mathbf{a}}$ Seleção \\
\hline Época (dias) & 30 a 45 & 60 a 75 \\
Rendimento (funcionário/dia) & 80 bandejas de 224 mudas & 120 bandejas de 96 mudas \\
Funcionários envolvidos na atividade & 10 selecionando e & 16 selecionando e \\
Peso da bandeja vazia (kg) & 1 encanteirando & 1 encanteirando \\
Peso da bandeja com 48 mudas (kg) & 1,4 & 1,1 \\
Peso da bandeja com 96 mudas (kg) & - & 3,4 \\
Peso da bandeja com 224 mudas (kg) & 10,0 & 5,9 \\
Peso da mesa (kg) & 12,0 & - \\
Comprimento dos canteiros (m) & 35,0 & 12,0 \\
\hline
\end{tabular}

Tabela 2. Etapas da atividade de seleção de mudas.

Table 2. Stages of the activity of seedlings selection.

\begin{tabular}{ll}
\hline Etapas & Descrição \\
\hline Deslocamento & $\begin{array}{l}\text { Caminhamento transcorrido dentro do viveiro para mudança de atividades } \\
\text { Consiste em retirar as mudas mortas, por raízes deformadas ou doenças, e separar as } \\
\text { mudas por tamanho de mudas }\end{array}$ \\
Irrigação & $\begin{array}{l}\text { Fornecimento controlado de água para as plantas em quantidade suficiente e no momento } \\
\text { certo }\end{array}$ \\
Parada operacional & $\begin{array}{l}\text { Consiste em pegar e transportar bandejas e caixas na lateral das quadras ou próximas aos } \\
\text { canteiros }\end{array}$ \\
Parada obrigatória & Horário de almoço de 1 hora com mais duas pausas de 15 minutos cada \\
\hline
\end{tabular}

Foram realizadas amostragens semanais de 1 hora em cada atividade de seleção, entre os meses de julho e setembro, com o auxílio de um cronômetro. Os tempos gastos em cada atividade parcial foram anotados em planilha. Os resultados foram extrapolados para uma jornada diária de trabalho de 9,8 horas.

Para a análise da viabilidade econômica da construção de um barracão coberto, no valor de $\mathrm{R} \$ 350.000,00$, onde as atividades de seleção de mudas seriam realizadas, foram empregados os indicadores valor presente líquido (VPL) e taxa interna de retorno (TIR), que consideram a variação do capital no tempo. Segundo determinação de metodologia da empresa, o período de avaliação deve ser de 5 anos, com taxa de $8 \%$ ao ano.

\section{Valor presente líquido (VPL)}

O valor presente líquido (VPL) é a soma do valor presente das receitas menos a soma do valor presente dos custos (DAVIS; JOHNSON, 1987).

$$
V P L=\sum_{j=0}^{n} R_{j}(1+i)^{-j}-\sum_{j=0}^{n} C_{j}(1+i)^{-j}
$$

em que: $C_{j}=$ custo no final do ano $j$;

$R_{j}=$ receita no final do ano $j$;

$i=$ taxa de juros; $n=$ duração do projeto, em anos.

\section{Taxa interna de retorno (TIR)}

A taxa interna de retorno (TIR) é a taxa de desconto que iguala o valor presente das receitas ao valor presente dos custos, ou seja, iguala o VPL a zero (REZENDE; OLIVEIRA, 2001). Também pode ser entendida como a taxa percentual de retorno do capital investido.

$$
\sum_{j=0}^{n} R_{j}(1+T I R)^{-j}=\sum_{j=0}^{n} C_{j}(1+T I R)^{-j}
$$


em que: $C_{j}=$ custo no final do ano $\mathrm{j}$;

$R_{j}=$ receita no final do ano j;

$n=$ duração do projeto, em anos.

Considerando o valor pago ao funcionário por dia trabalhado, fez-se uma proporção do tempo pago e não trabalhado e extrapolou-se esse valor para toda a equipe envolvida na atividade, sendo 10 funcionários na $1^{\mathrm{a}}$ seleção e 16 funcionários na $2^{\mathrm{a}}$ seleção, em um mês, um ano e cinco anos, que foi o tempo considerado para a depreciação de estruturas. Em resumo, na análise de viabilidade econômica, o custo foi referente ao valor da construção do galpão, e as receitas referem-se às economias devido aos possíveis ganhos de rendimento das atividades de $1^{\mathrm{a}}$ e $2^{\mathrm{a}}$ seleção, se realizadas em ambiente coberto.

\section{RESULTADOS E DISCUSSÕES}

\section{Estudo de tempo e movimento}

Primeira seleção

Os dados coletados consideram o tempo integral dos trabalhadores desde a chegada ao local de trabalho, totalizando 9,8 horas (588 minutos). Foram observadas e anotadas todas as atividades e paradas ocorridas nesse período de medição e agrupadas (Tabela 3).

Tabela 3. Tempo utilizado na realização das parciais da primeira seleção.

Table 3. Time used in partial fulfillment of the first selection.

\begin{tabular}{lcc}
\hline \multirow{2}{*}{ Etapas } & \multicolumn{2}{c}{ Tempos } \\
\cline { 2 - 3 } & Minutos & \% \\
\hline Deslocamento & 31 & 5,3 \\
Seleção de mudas & 310 & 52,7 \\
Irrigação & 38 & 6,5 \\
Parada operacional & 119 & 20,2 \\
Parada obrigatória & 90 & 15,3 \\
\hline Total & 588 & 100,0 \\
\hline
\end{tabular}

Nota-se que o trabalhador executou a sua atividade em apenas $52,7 \%$ do seu tempo. Os $20,2 \%$ do tempo medido foram gastos com deslocamento para buscar e levar as bandejas próximas ao local de seleção; em 6,5\% do tempo, o trabalhador ficou à espera para retomar sua atividade após o período de irrigação; e 5,3\% foram consumidos com deslocamentos nas dependências do viveiro. Os 15,3\% do tempo restante são de paradas obrigatórias (como horário de almoço de 1 hora e duas pausas de 15 minutos cada), exigidas por lei e pela empresa, que não foram utilizados no cômputo de rendimentos.

Somando-se os tempos mencionados acima, temos que o tempo produtivo da primeira seleção equivaleu a $52,7 \%$ do tempo de trabalho (5 horas e 10 minutos) e, como tempo auxiliar e paradas não operacionais, $47,3 \%$ (4 horas e 38 minutos). Portanto, a produção de mudas ocorre apenas durante pouco mais que a metade da jornada de trabalho.

Segunda seleção

Os mesmos critérios foram adotados para a medição realizada na segunda seleção. A tabela 4 mostra o consumo do tempo, em porcentagem, das classes de tempo analisadas na atividade de segunda seleção.

Tabela 4. Valores percentuais das classes de tempo analisadas na atividade de segunda seleção.

Table 4. Percentage values of the time classes analyzed in the activity of the second selection.

\begin{tabular}{lcc}
\hline \multirow{2}{*}{ Etapas } & \multicolumn{2}{c}{ Tempos } \\
\cline { 2 - 3 } & Minutos & \% \\
\hline Deslocamento & 13 & 2,2 \\
Seleção de mudas & 406 & 69,1 \\
Irrigação & 18 & 3,1 \\
Parada operacional & 58 & 9,9 \\
Parada obrigatória & 93 & 15,7 \\
\hline Total & 588 & 100,0 \\
\hline
\end{tabular}


Nota-se um maior percentual de tempo produtivo na segunda seleção $(69,1 \%)$ em relação à primeira. Isso ocorre porque nessa fase as mudas não necessitam de irrigações constantes, utilizando-se apenas $3,1 \%$ do tempo na irrigação. Houve pequenas interrupções ao longo do ciclo, no entanto a maior encontrada foi o rendimento operacional pelo trabalhador. Foram consumidos 9,9\% do tempo com deslocamentos para transporte das bandejas até o canteiro a ser selecionado e 2,2\% do tempo o trabalhador gastou com locomoção nas dependências do viveiro.

Somando-se os tempos mencionados acima, temos que o tempo produtivo ocorreu em $69,1 \%$ da jornada de trabalho (6 horas e 46 minutos), sendo de 30,9\% ( 3 horas e 2 minutos) o tempo auxiliar e de paradas não operacionais.

O tempo consumido com deslocamento varia de trabalhador para trabalhador. Já o tempo de irrigação pode variar em função do dia e da época do ano. No verão ocorreram mais interrupções em função das altas temperaturas e consequente necessidade de mais irrigações. Experimento realizado por Freitag (2007) com produção de mudas de Eucalyptus grandis demonstrou que a utilização de frequência de três irrigações por dia gerou mudas com melhor desenvolvimento em altura, maior número de plantas por bandeja e maior número de folhas por plantas durante as sete épocas de avaliação. Segundo Braga e Calgaro (2010), a frequência de irrigação - turno de rega - pode variar de acordo com as condições de solo, clima, variedade e estádio de desenvolvimento da cultura.

\section{Análise de rendimentos}

Para a quantificação dos possíveis ganhos em rendimento dentro das atividades pesquisadas, foram somados os tempos consumidos com as atividades parciais não produtivas (tempos auxiliares e tempos não operacionais) aos tempos produtivos, para possibilitar a análise de rendimento (Tabela 5). Essa soma de tempos reflete a realidade que se teria caso essa atividade fosse realizado em um local fixo e coberto. Portanto, não ocorreriam mais deslocamentos dos funcionários, pois eles ficariam fixos no galpão. Não aconteceriam paradas para irrigações durante a atividade de seleção dentro do barracão, pois as irrigações ocorrem somente nas quadras. O transporte de bandejas seria realizado por um trator que já está contemplado no contrato de atividades do viveiro.

Tabela 5. Resultados da transformação hipotética dos tempos não produtivos em produtivos.

Table 5. Results of hypothetical conversion of non-productive time into productive.

\begin{tabular}{lll}
\hline & Primeira seleção (minutos) & Segunda seleção (minutos) \\
\hline Tempo auxiliar e paradas não operacionais & 150 & 71 \\
Paradas obrigatórias & 90 & 90 \\
Tempo produtivo real & 348 & 427 \\
Tempo produtivo simulado & 498 & 498 \\
\hline Total & 588 & 588 \\
\hline
\end{tabular}

Os tempos não produtivos nada mais são que os tempos perdidos por essa atividade quando realizada em ambiente aberto, com as interrupções de irrigação e de deslocamentos para a busca dos materiais para a realização do trabalho, o que não seria necessário se o trabalho fosse realizado dentro de um galpão.

As irrigações dentro do galpão seriam realizadas apenas nas mudas antes de serem selecionadas, não expondo o trabalhador à irrigação, assim como as bandejas e caixas. Os equipamentos necessários à atividade ficariam próximos às mesas de seleção, pois elas passariam a ser fixas, evitando também o deslocamento constante dos trabalhadores.

No viveiro, cada trabalhador faz, em média, 84 bandejas com 224 mudas cada por dia na primeira seleção, sendo que o tempo produtivo gasto por trabalhador é de aproximadamente 4 minutos por bandeja. Na segunda seleção, o rendimento por dia é de 120 bandejas com 96 mudas cada, dando uma média de 3,5 minutos por bandeja.

Para a simulação do rendimento, foram somados os tempos não produtivos (tempos auxiliares e tempos não operacionais) com os tempos produtivos, obtendo-se o tempo produtivo hipotético (se realizados os trabalhos de seleção sob um galpão). Os rendimentos operacionais (mudas/dia/trabalhador) simulados nessa nova condição são apresentados na figura 3 . 


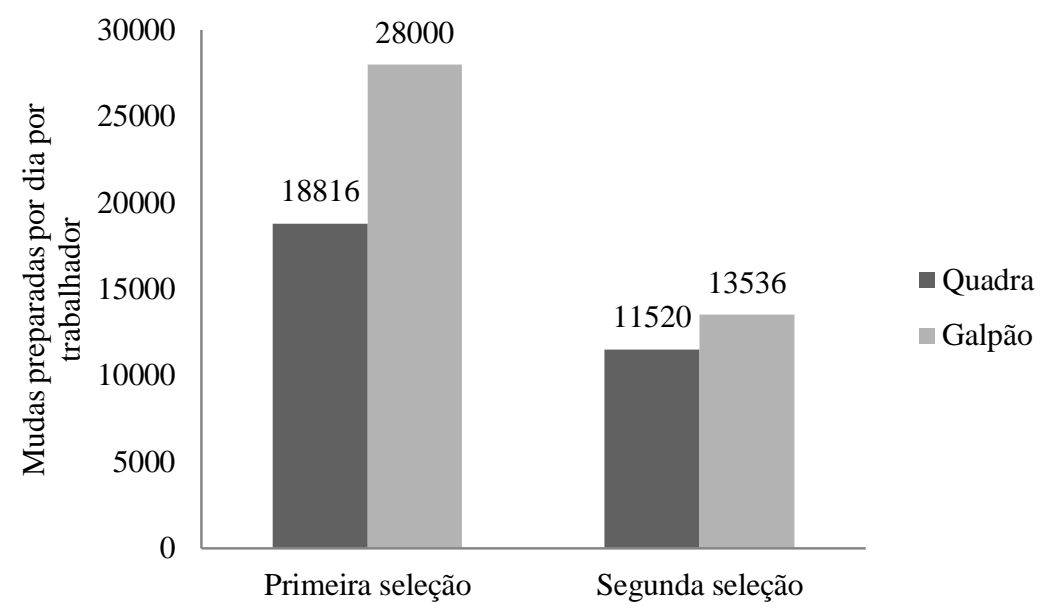

Figura 3. Rendimento operacional simulado utilizando o tempo produtivo hipotético.

Figure 3. Simulated operational performance using hypothetical productive time.

Para a primeira seleção de mudas, houve um aumento de 9184 mudas preparadas por dia por trabalhador quando utilizado um ambiente coberto (galpão), e, para a segunda seleção, um acréscimo de 2016 mudas preparadas a mais por dia para cada trabalhador. Nota-se um aumento hipotético de 48,8\% no rendimento da primeira seleção e de $17,5 \%$ na segunda seleção.

Zani Filho et al. (1989) relataram um aumento de 33\% na primeira seleção e 0\% na segunda, em função da mudança de layout do viveiro. Porém esses aumentos foram conseguidos somente com setorização das operações, utilizando a mesma estrutura física do viveiro.

Simões e Silva (2010) descreveram um rendimento operacional de $0,337 \mathrm{HH} / \mathrm{mil}$ mudas na etapa de seleção de mudas, enquanto que, neste estudo, o rendimento da primeira seleção foi de $0,468 \mathrm{HH} / \mathrm{mil}$ mudas e $0,764 \mathrm{HH} /$ mil mudas na segunda seleção, portanto um pouco menor que o relatado pelos autores mencionados acima. No galpão, os rendimentos subirão para $0,314 \mathrm{HH} /$ mil mudas na primeira e $0,650 \mathrm{HH} /$ mil mudas na segunda seleção.

Os ganhos de seleção foram considerados a partir de uma situação hipotética, em que os tempos auxiliares (irrigação e transporte de bandejas) e paradas não operacionais (deslocamento de funcionários dentro do viveiro) seriam transformados em atividade produtiva (seleção de mudas), devido à nova metodologia aplicada no barracão, conforme descrito anteriormente. Julgou-se que tal aumento de rendimento seja viável tecnicamente, porém um estudo de tempos e movimentos utilizando a nova metodologia de seleção no ambiente coberto se faz necessário para cálculo dos ganhos reais.

\section{Analise de viabilidade econômica}

A tabela 6 ilustra os valores em reais calculados através da planilha de diárias do ano de 2010 informada pelo prestador de serviços. Os valores estipulados não estão corrigidos para os demais anos.

Tabela 6. Custo do tempo parado em função da diária paga por funcionário.

Table 6. Cost of downtime according to the daily rate paid per employee.

\begin{tabular}{lcc}
\hline Custo proporcional à diária & Primeira seleção (R\$) & Segunda seleção (R\$) \\
\hline Custos das paradas em função das diárias & 40,20 & 19,30 \\
Economia no mês por equipe & $8.442,38$ & $6.393,70$ \\
Economia no ano & $101.308,55$ & $76.724,35$ \\
Economia em 5 anos & $709.159,88$ & $537.070,42$ \\
\hline
\end{tabular}

A figura 4 indica o fluxo de caixa para os 5 anos de investimento para uma taxa de desconto de 8,0\% ao ano, segundo Weighted Average Cost Of Capital (WACC, 2010). 


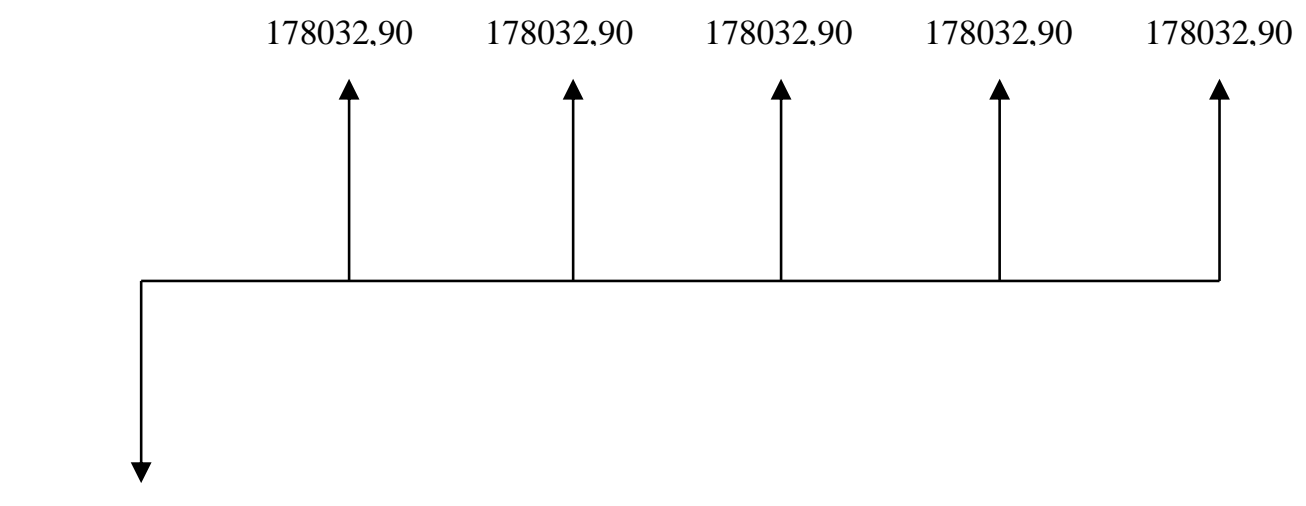

350000,00

Figura 4. Fluxo de caixa para um horizonte de planejamento de cinco anos à taxa de $8 \%$ ao ano (WACC em julho de 2010). $\mathrm{R} \$ 350.000,00$ refere-se ao investimento no barracão e $\mathrm{R} \$ 178.032,90$ refere-se ao retorno anual do investimento.

Figure 4. Cash flow for a planning horizon of five years and a rate of $8 \%$ per year (WACC in July 2010). $\mathrm{R} \$ 350,000.00$ refers to the investment in the protected environment and $\mathrm{R} \$ 178,032.90$ refers to annual return on investment.

No início do investimento, foram necessários $\mathrm{R} \$ 350.000,00$ para a construção do galpão utilizando a taxa de desconto de $8 \%$ ao ano. No primeiro ano, foi possível obter uma receita de $\mathrm{R} \$ 178.032,90$, sendo esse retorno esperado por ano ao longo de todo o horizonte de planejamento (cinco anos).

Dessa forma, é viável a construção do galpão para seleção de mudas, por apresentar um VPL positivo (R\$ 119.150,27) e uma TIR média $(14,5 \%)$ maior que a taxa de desconto WACC vigente $(8 \%)$.

Os resultados de VPL e TIR foram obtidos levando-se em conta o padrão de avaliação da empresa, em que se considera um período de 5 anos e taxa de $8 \%$ ao ano. Os resultados poderão ser menores, com um prazo para o retorno do investimento maior, caso haja alteração nos parâmetros utilizados.

\section{CONCLUSÕES}

- A construção do galpão propiciou melhoria das condições ergonômicas aos trabalhadores das atividades de primeira e segunda seleção de mudas, devido à eliminação de atividades críticas, bem como realização das atividades em ambiente protegido. Com isso, houve uma redução do desperdício de tempo, pois os tempos não operacionais de espera e deslocamento foram remanejados para a seleção de mudas.

- Com base nos ganhos de rendimento calculados e na análise de viabilidade econômica, conclui-se que o investimento na construção do galpão para o setor de seleção de mudas é viável e que o retorno desse investimento acontecerá em dois anos, com VPL positivo de R $\$ 119.150,27$ e TIR de 14,5, a uma taxa de $8 \%$ ao ano.

\section{REFERÊNCIAS}

ALVES, J. U.; MINETTI, L. J.; SOUZA, A. P.; SILVA, K. R.; GOMES, J. M.; FIEDLER, N. C. Avaliação do ambiente de trabalho na propagação de Eucalyptus spp. Revista Brasileira de Engenharia Agrícola e Ambiental. Campina Grande, v. 6, n. 3, p. 481 - 486, 2002.

BARNES, R. M. Estudo de Movimentos e de Tempos, Projeto e Medida de Trabalho. Tradução da $6^{\text {a }}$ edição americana, Editora Edgard Blücher Ltda., 1977.

BRAGA, M. B.; CALGARO, M. Sistema de produção de melancia. Disponível em: <http://sistemasde producao.cnptia.embrapa.br/FontesHTML/Melancia/SistemaProducaoMelancia/>. Acesso em: 31/08/2011. 
BRAZ, E. M. Subsídios para o planejamento do manejo de florestas da Amazônia. 236 f. Tese (Doutorado em Engenharia Florestal) - Universidade Federal de Santa Maria, Santa Maria, RS, 2010.

CARNEIRO, J. G. A. Produção e controle de qualidade de mudas florestais. Curitiba: UFPR/FUPEF; Campos dos Goytacazes, UENF, 1995. 451 p.

DAVIS, L. S.; JOHNSON, K. N. Forest management. New York: McGraw-Hill, 3. ed., 1987. 789 p.

FERREIRA, E. M.; ALFENAS, A. C.; MAFIA, R. G.; LEITE, H. G.; SARTÓRIO, R. C.; PENCHEL FILHO, R. M. Determinação do tempo de enraizamento de miniestacas de clones de Eucalyptus spp. Revista Árvore, Viçosa, MG, v. 28, n. 2, p. 183 - 187, 2004.

FREITAG, A. S. Frequências de irrigação para Eucalyptus grandis e Pinus elliottii em viveiro. $60 \mathrm{f}$. Dissertação (Mestrado em Engenharia Agrícola) - Universidade Federal de Santa Maria, Santa Maria, RS, 2007.

FIEDLER, N. C. Análise de postura e esforços despendidos em operações de colheita florestal no norte do estado da Bahia. 103 f. Tese (Doutorado em Ciências Florestal) - Universidade Federal de Viçosa, Viçosa, 1998.

FIEDLER, N. C.; FERREIRA, A. H. S.; VENTUROLI, F.; MINETTE, L. J. Avaliação da carga de trabalho físico exigido em operações de produção de mudas ornamentais do Distrito Federal - Estudo de Caso. Revista Árvore. Viçosa, MG, v. 31, n. 4, p. 703 - 708, 2007.

GAGO, N.; CORTE, J. S. Carregamento e transporte de cana-de-açúcar: comparação de sistemas alternativos. In: Seminário de Tecnologia Agronômica, n 3, 1986, Piracicaba. Anais... São Paulo: COPERSUCAR, 1986. p. 489 - 522.

MARTINS, R. C. C.; JACINTO, J. M. M.; MARTINS, I. S. Viveiros Florestais. Brasília: Universidade de Brasília, 1998. 22 p.

MELO. L. A. Armazenamento, aplicação de antioxidantes e otimização do tempo em casa de vegetação no enraizamento de miniestacas de híbridos de Eucalyptus grandis. $58 \mathrm{f}$. Tese (Doutorado em Ciências Florestais) - Universidade Federal de Viçosa, Viçosa, 2009.

MONTEIRO, M. A. M. Importância da ergonomia na saúde dos funcionários de unidades de alimentação e nutrição. Revista Baiana de Saúde Pública, Salvador, BA, v. 33, n. 3, 2009.

REZENDE, J. L. P.; OLIVEIRA, A. D. Análise econômica e social de projetos florestais. Viçosa: Universidade Federal de Viçosa, 2001. 389 p.

RUDNER, U. M \& R Consultoria e Treinamento. Disponível em: <http://www.mr.com.br /Artigos/ArtigosMr.aspx?ida=17\&idc=1>. Acesso em: 02/06/2011.

SCHORN, L. A.; FORMENTO, S. Produção de mudas florestais. Blumenau: Universidade Regional de Blumenau, Centro de Ciências Tecnológicas, Departamento Engenharia Florestal (Apostila). 2003, 52 p.

SIMÕES, D.; SILVA, M. R. Análise técnica e econômica das etapas de produção de mudas de eucalipto. Revista Cerne, v. 16, p. 359 - 366, 2010.

VIEIRA, S. D. G. Análise ergonômica do trabalho em uma empresa de fabricação de móveis tubulares. Dissertação (Mestrado em Engenharia de Produção) - Universidade Federal de Santa Catarina, Florianópolis, SC, 1997.

XAVIER, A.; COMÉRIO, J. Microestaquia: uma maximização da micropropagação de Eucalyptus. Revista Árvore, Viçosa, v. 20, n. 1, p. 9 - 16, 1996.

ZANI FILHO, J.; BALONI, E. A.; STAPE, J. L. Viveiro de mudas florestais: análise de um sistema operacional atual e perspectivas futuras. Circular Técnica IPEF, n. 167, p. 1 - 5, 1989. 